\title{
Haemolytic crisis in G6PD-deficiency triggered by recreational use of synthetic cannabis
}

\author{
Amy J Halliday, Khai Li Chai, Kate H Hurley, Slavisa Ninkovic, Aaron Bloch, Hang Quach \\ Department of Haematology, St Vincent's Hospital, Victoria, Australia
}

Received: December 23, 2015

Accepted: February 8, 2016

Online Published: February 18, 2016

DOI: $10.5430 /$ crim.v3n1p67

URL: http://dx.doi.org/10.5430/crim.v3n1p67

\begin{abstract}
Glucose-6-phosphate dehydrogenase (G6PD) deficiency is the most common inherited cause of haemolytic anaemia. Recognition and avoidance of haemolytic triggers is an important part of management, both during haemolytic crises and in the long-term. We report a case of haemolytic crisis in a patient with previously undiagnosed G6PD-deficiency, triggered by the use of synthetic cannabis in the form of "spice". To our knowledge, this is the first report of G6PD deficiency-related haemolytic crisis triggered by synthetic cannabinoids.
\end{abstract}

Key Words: G6PD deficiency, Synthetic cannabinoids, Spice, Haemolysis

\section{INTRODUCTION}

Glucose-6-phosphate dehydrogenase (G6PD) deficiency is the most common inherited cause of haemolytic anaemia, affecting up to 400 million people worldwide. ${ }^{[1]}$ Some patients can be asymptomatic for most of their lives and unaware of their underlying condition, and present suddenly with acute serious haemolytic episodes. These episodes are most commonly triggered by exposure to medications, such as antimalarials or antibiotics, chemicals such as naphthalene found in mothballs, and exposure to certain foods, including legumes or fava beans. ${ }^{[2]}$ Haemolysis can also be triggered by infections, which increase oxidative stress. Identifying the trigger is important for both treatment and prevention of recurrent haemolytic crises.

While exposure to recreational substances such as nitrite inhalants have been described as triggers of oxidative haemolysis, ${ }^{[3,4]}$ synthetic cannabinoids have not been implicated as triggers of acute haemolysis.
We describe a case of oxidative haemolysis in a young man with previously undiagnosed G6PD deficiency most likely triggered by recreational use of synthetic cannabinoids in the form of "spice".

\section{Case PResentation}

A 33-year-old Omani man of no fixed abode presented to the emergency department with a 3-day-history of worsening fatigue, dyspnoea on minimal exertion, and pre-syncopal episodes. He also described palpitations, mild fevers and sweats, and dark urine. He had no localising infective symptoms, no recent illnesses, no recent travel or sick contacts. He had previously been well apart from childhood asthma, and he was on no regular medications.

Full blood examination revealed a haemoglobin of $54 \mathrm{~g} / \mathrm{L}$ with a reticulocytosis of $275 \times 10^{5} / \mathrm{L}$, white cell count of $24.8 \times 10^{9} / \mathrm{L}$, neutrophil count of $17.7 \times 10^{9} / \mathrm{L}$, and platelets of $473 \times 10^{9} / \mathrm{L}$. As shown in Figure 1, his blood film demon-

${ }^{*}$ Correspondence: Amy J Halliday; Email: amyjhalliday@gmail.com; Address: Department of Haematology, St Vincent’s Hospital, 41 Victoria Parade, Fitzroy, Victoria 3065, Australia.

Published by Sciedu Press 
strated bite cells and helmet cells with significant polychromasia, suggestive of oxidative haemolysis. A haemolysis screen revealed elevated lactate dehydrogenase (LD) 426 $\mathrm{U} / \mathrm{L}$, haptoglobin $<0.1 \mathrm{~g} / \mathrm{L}$, and an elevated bilirubin of 78 $\mu \mathrm{mol} / \mathrm{L}$ that was largely unconjugated $(81 \%)$. Coomb's test was negative. Reduced G6PD activity on spot fluorescence screening was confirmed on G6PD spectrophotometric assay, that demonstrated a G6PD level of $2.7 \mathrm{U} / \mathrm{g}$ of haemoglobin (normal range 8.8-17.6). His renal function was normal (creatinine of $82 \mu \mathrm{mol} / \mathrm{L}$, urea of $4.3 \mathrm{mmol} / \mathrm{L}$ ), and remained so throughout the admission. Of note, the patient had no known family history of G6PD deficiency or haemolytic anaemia.

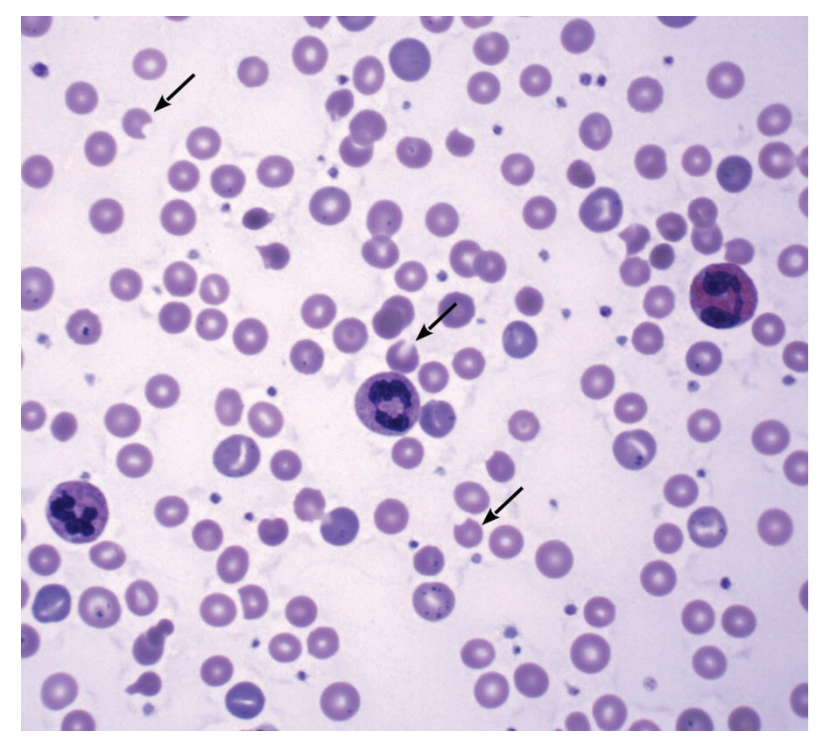

Figure 1. Blood film. The patient's blood film taken on admission, demonstrating bite cells (arrows) with significant polychromasia

No exposure to common triggers of oxidative haemolysis was identified, including no recent exposure to fava beans or legumes, or new medications including antibiotics or antimalarials. The only recent change was in the patient's habit of cannabis consumption. He previously smoked marijuana but ceased one year ago, at which point he began smoking synthetic cannabis in the form of "spice". He initially smoked $1 \mathrm{~g} /$ day, but in the preceding few weeks had increased this to around $2 \mathrm{~g} / \mathrm{day}$. He smoked many various brands (around eight) dependent upon supply, which he obtained through his social network on the streets.

The patient's haemoglobin level reached a nadir of $49 \mathrm{~g} / \mathrm{L}$ during his inpatient stay upon which he was given 2 units of packed red blood cells. With no further intervention except the cessation of his usual synthetic cannabis, haemolysis spontaneously settled. His LD and bilirubin fell over the following four days as he mounted a significant reticulocyte response and steady improvement in $\mathrm{Hb}$, as illustrated in Figure 2. The patient was discharged on day four without further transfusions. Of note, his urine drug screen was positive for benzodiazepines, but negative for all other drugs tested including cannabinoids.

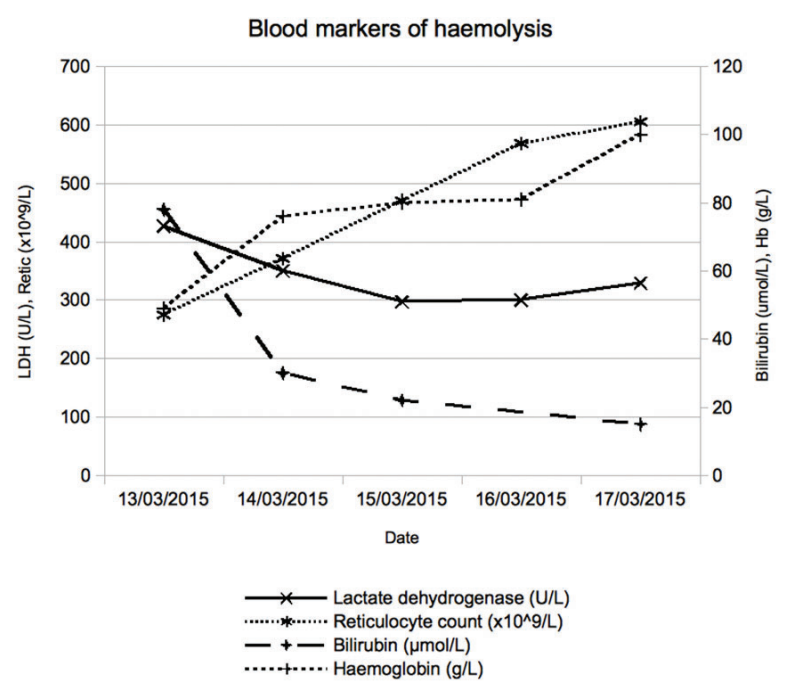

Figure 2. Blood markers of haemolysis. Changes in blood markers of haemolysis from the time of admission to discharge

LDH: lactate dehydrogenase; Retic: reticulocyte count; $\mathrm{Hb}$ : haemoglobin.

\section{Discussion}

This case describes an episode of acute haemolysis in a patient with previously undiagnosed G6PD deficiency in the setting of recent use of substantial quantities of synthetic marijuana. To our knowledge, this is the first report of G6PD deficiency-related haemolytic crisis that is triggered by synthetic cannabinoids.

Synthetic cannabinoids are a large, structurally heterogeneous group of manufactured substances that bind either the C1 or C2 cannabinoid receptor. ${ }^{[5]}$ Synthetic cannabinoids sprayed onto dried plant material (traditionally herbs) is referred to as "spice", which is smoked to get the effects of the synthetic cannabinoids. ${ }^{[6]}$ The synthetic cannabinoids are a large and structurally heterogeneous group of chemicals, which can be classified as either classical cannabinoids, including tetrahydrocannabinol $(\Delta 9$-THC) and other constituents of cannabis, and their structurally related synthetic analogues; or non-classical cannabinoids, which are structually unrelated to $\Delta 9$-THC. Recreational use of the non-classical cannabinoids is increasing, as producers evolve their product to evade regulations which ban classical synthetic cannabinoids. Interestingly, many of the more recently developed synthetic cannabinoids are naphthalenes; indeed, 
four out of the seven sub-categories of synthetic cannabinoids as classified by the British Advisory Council on the Misuse of Drugs are naphthalenes. ${ }^{[7]}$ These naphthalene synthetic cannabinoids are becoming more frequent as an ingredient in spice, parallelling the overall trend towards increasing recreational use of non-classical cannabinoids. A study in Europe found that $23 \%$ of spice products prior to 2009 contained at least one naphthalene cannabinoid, and that this increased to $39 \%$ after January 2009 when laws were introduced banning some forms of early synthethic cannabinoids. ${ }^{[8]}$ More recently, $99.4 \%$ of spice mixtures seized by the Istanbul Narcotic Department between 2010 and 2012 contained a naphthalene synthetic cannabinoid. ${ }^{[9]}$

Naphthalene, a constituent of moth-balls, is a well-described oxidative trigger when inhaled by patients with G6PD deficiency. ${ }^{[2]}$ Its metabolite naphthaloquinine, a molecule found in henna, is an even more potent trigger of haemolysis in these patients. ${ }^{[10-12]}$ The mechanism is not currently understood, but has been hypothesised to be due to naphthalene binding of glutathione, reducing available stores. It is possible that naphthalene synthetic cannabinoids may have been the trigger for haemolysis in the present case. Given the increasing popularity of these ingredients with illegal manufacturers and the patient's use of numerous brands of synthetic cannabis in the preceding weeks, it is very possible that he had recently been exposed to a naphthalene cannabinoid. The patient's recent increase in consumption, use of multiple brands and the frequent changes in active ingredients in these products may explain why this patient presented at the present time despite having smoked these products for the preceding year. Unfortunately the patient was unable to provide the product for testing in the present case, and we were not able to confirm the content of the spice mixture.
Given that we were unable to analyse the spice mixture in the present case, it is possible that this contained either a classical synthetic cannabinoid, or no synthetic cannabinoids. Whilst this is a major limitation of the present study, it is of interest that the urine drug screen (UDS) performed in the present case was negative for $\Delta 9$-THC. Many non-classical synthetic cannabinoid metabolites are not detectable on routine UDS, ${ }^{[13]}$ and therefore the negative UDS does not exclude the recent consumption of a non-classical synthetical cannaboid. It also indicates that the cannabinoid smoked in the present case was unlikely to be $\Delta 9$-THC or a structurally related compound; however, it does not exclude the possibility that the patient consumed a classical cannabinoid that was not detected. The classical synthetic cannabinoids have likewise not been linked with oxidative haemolysis previously, and may have been the novel trigger in the present case. However, we feel that the increasing prevalence of napthalenes in spice mixtures and the known association of napthalenes with oxidative haemolysis in G6PD make this a more plausible proposition. Another possibility is that the spice mixture did not contain a synthetic cannabinoid, and a contaminant in the preparation or herbal ingredient induced oxidative haemolysis in the present case. In vitro examination of the oxidative effects of these spice mixtures would assist in answering these questions.

Currently, synthetic cannabis is not recognized as one of the common triggers of haemolytic crisis in patients with G6PD deficiency. ${ }^{[2]}$ This case highlights the need to consider such a trigger especially when the use of synthetic cannabis as a recreational drug is on the increase. ${ }^{[14]}$ In conclusion, the recreational use of synthetic cannabis should be considered as a potential trigger for seemingly idiopathic cases of oxidative haemolysis, especially in patients with G6PD deficiency.

\section{REFERENCES}

[1] Nkhoma ET, Poole C, Vannappagari V, et al. The global prevalence of glucose-6-phosphate dehydrogenase deficiency: a systematic review and meta-analysis. Blood Cells Mol Dis. 2009; 42(3): 26778. PMid:19233695 http://dx.doi.org/10.1016/j.bcmd. 20 08.12 .005

[2] Italian G6PD Deficiency Association. Drugs that should be avoidedOfficial List [Internet]. 2015. Available from: http://www.g6pd.o rg/en/G6PDDeficiency/SafeUnsafe/DaEvitare_ISS-it

[3] Neuberger A, Fishman S, Golik A. Hemolytic anemia in a G6PDdeficient man after inhalation of amyl nitrite ("poppers"). Isr Med Assoc J IMAJ. 2002; 4(11): 1085-6. PMid:12489514

[4] Beaupre SR, Schiffman FJ. Rush hemolysis. A "bite-cell" hemolytic anemia associated with volatile liquid nitrite use. Arch Fam Med. 1994; 3(6): 545-8. http://dx.doi.org/10.1001/archfami.3. 6.545

Published by Sciedu Press
[5] Fantegrossi WE, Moran JH, Radominska-Pandya A, et al. Distinct pharmacology and metabolism of K2 synthetic cannabinoids compared to $\Delta(9)$-THC: mechanism underlying greater toxicity? Life Sci. 2014; 97(1): 45-54. PMid:24084047 http://dx.doi.org/1 $0.1016 / j . l f s .2013 .09 .017$

[6] Zawilska JB, Wojcieszak J. Spice/K2 drugs-more than innocent substitutes for marijuana. Int J Neuropsychopharmacol Off Sci J Coll Int Neuropsychopharmacol CINP. 2014; 17(3): 509-25. http: //dx.doi.org/10.1017/s1461145713001247

[7] Advisory Council on the Misuse of Drugs. ACMD report on the major cannabinoid agonists [Internet]. Advisory Council on the Misuse of Drugs. 2009. Available from: https: //www.gov.uk/government/uploads/system/uploads/att achment_data/file/119149/acmd-report-agonists.pdf

[8] Dresen S, Ferreirós N, Pütz M, et al. Monitoring of herbal mixtures potentially containing synthetic cannabinoids as psychoac- 
tive compounds. J Mass Spectrom JMS. 2010; 45(10): 1186-94. PMid:20857386 http://dx.doi.org/10.1002/jms.1811

[9] Gurdal F, Asirdizer M, Aker RG, et al. Review of detection frequency and type of synthetic cannabinoids in herbal compounds analyzed by Istanbul Narcotic Department of the Council of Forensic Medicine, Turkey. J Forensic Leg Med. 2013; 20(6): 667-72. PMid:23910858 http://dx.doi.org/10.1016/j.jflm.2013.03.041

[10] Kandil HH, al-Ghanem MM, Sarwat MA, et al. Henna (Lawsonia inermis Linn.) inducing haemolysis among G6PD-deficient newborns A new clinical observation. Ann Trop Paediatr. 1996; 16(4): 287-91.

[11] Kök AN, Ertekin MV, Ertekin V, et al. Henna (Lawsonia inermis Linn.) induced haemolytic anaemia in siblings. Int J Clin Pract. 2004; 58(5): 530-2. http://dx.doi.org/10.1111/j.1368-5031.20 $04.00048 . x$
[12] Raupp P, Hassan JA, Varughese M, et al. Henna causes life threatening haemolysis in glucose-6-phosphate dehydrogenase deficiency. Arch Dis Child. 2001; 85(5): 411-2. PMid:11668106 http://dx.d oi.org/10.1136/adc.85.5.411

[13] Arntson A, Ofsa B, Lancaster D, et al. Validation of a Novel Immunoassay for the Detection of Synthetic Cannabinoids and Metabolites in Urine Specimens. J Anal Toxicol. 2013; 37(5): 284-90. http://dx.doi.org/10.1093/jat/bkt024

[14] Advisory Council on the Misuse of Drugs. ACMD: further consideration of the synthetic cannabinoids [Internet]. 2012 Available from: https://www.gov.uk/government/uploads/ system/uploads/attachment_data/file/119042/synthet ic-cannabinoids-2012.pdf 